\title{
On a New Ciliate, Ptyssostoma thalassemae nov. gen., nov. sp., from the Intestine of the Echiuroid Worm, Thalassema neptuni Gärtner.
}

\author{
By
}

\section{C. Hentschel, M.Sc., F.L.S.,}

Demonstrator in Biology at St. Bartholomew's Hospital Medical College, London.

(From the Zoological Laboratory, King's College, London.)

With 3 Figures in the Text.

THE intestine of the Echiuroid worm, Thalassema neptuni Gärtner, is occasionally found at Plymouth to be infected with a small parasitic ciliate. I have searched the literature on the anatomy of Thalassema, but have been unable to find any reference to this Protozoon. In fact, I have not as yet come across any record of ciliates infesting the Gephyrea,* though Mr. Dobell has informed me that, some years ago, the late Professor Ikeda mentioned to him the presence of ciliates from some of the Gephyrea he was then studying; but I have not been able to find any reference to ciliates in Ikeda's papers on Japanese Gephyrea. Lankester (1881), in a paper on Thalassema, merely records the occurrence of a gregarine which $\mathrm{I}$ also have observed in a number of specimens from the neighbourhood of Plymouth. I am, therefore, led to the conclusion that this ciliate must be new, and I have decided to name it Ptyssostoma $\dagger$ thalassemce nov. gen., nov. sp.

The occurrence of this parasite at Plymouth seems somewhat erratic. I first observed it at the Marine Biological Laboratory in April, 1922, when two or three worms were found to contain the parasite. I did not get another opportunity of examining it again until Easter, 1925, when four out of five specimens were found to be infected. Among these I was lucky in discovering one quite heavy infection, though, as a rule, not more than about half a dozen ciliates were to be found in a single worm.

Since that time, during the summer of 1925, I had specimens of Thalassema sent to me in London from Plymouth, but I found no ciliates in

* Since the above was written, Professor Tregouboff, of the Marine Biological Laboratory at Villefranche, has kindly brought to my notice a ciliate, Cryptochilum Cuenoti, described by Florentin (1898) from the œsophagus of Phascolosoma vulgare Blainville. This ciliate is, however, quite distinct from the species under consideration. $\dagger \pi \tau \dot{\sigma} \sigma \epsilon \iota \nu$, to fold; $\sigma \tau \delta \dot{\mu} \mu$, a mouth. 
the two dozen examined. At first I was uncertain as to whether this negative result was due to the ciliates not standing the journey (though the worms seemed to be quite active and in good condition on arrival), or whether the worms were only infected in the spring. However, in April, 1926, I examined at Plymouth thirty-four worms without success. It looks, therefore, as though the occurrence of this ciliate is erratic, and not due to any localised infection; in 1925 it was found in worms from the littoral region both of Rum Bay (Plymouth Sound) and Wembury Bay, whereas I obtained Thalassema this year (1926) from both these areas and also dredged from deeper water in the Sound, but all were uninfected.

\section{DESCRIPTION.}

Ptyssostoma thalasseme (Fig. 1) inhabits the intestine of Thalassema neptuni. It is of a somewhat ovoid form, though it can change its shape to a certain extent, having a short prominence at its anterior end, which can

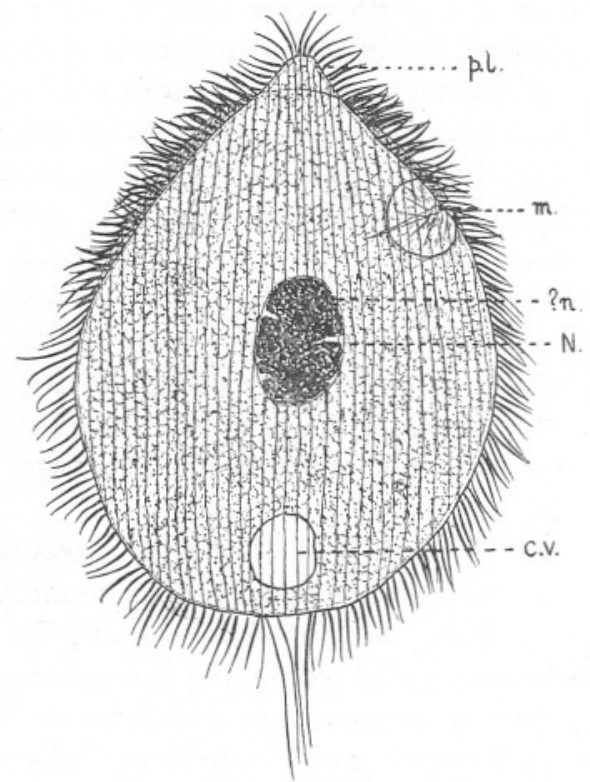

Frg. 1. A stained Ptyssostoma thalassema (Mayer's acid hæmalum and Orange G.) $\times 700$ approx.

c.v., contractile vacuole ; m., mouth; N., meganucleus; ? n., ? micronucleus; p.l., anterior projecting lobe.

be slightly extended or contracted. This prominence seems to overhang the anterior part of the animal and probably acts as a sort of tactile organ for feeling its way through the debris in the intestine. As a result of this, fixed and stained specimens tend to vary somewhat in outline. 
The body is not quite cylindrical, but is slightly flattened from side to side. The animal swims on one side, usually with the mouth, which is situated a little way posterior to the anterior prominence, on the right. As the ciliate turns over, one can see that the lower (i.e. left) side is slightly concave, whereas the upper (i.e. right) side is convex.

It is an active animal, burrowing its way in a determined manner through the debris in the intestine, like most intestinal ciliates. It will live for quite a considerable time on the slide, provided that there is no prolonged exposure to air ; but if a cover-slip is not placed over it quickly, it will die in a very short time.

Apart from the effects of the slight contractility that the animals possess, there is not much variation in the size of the individuals, the measurements ranging from about $75-100 \mu$ in length, and from $55-75 \mu$ in breadth.

It is not of any marked colour, the cytoplasm being merely of a transparent greyishness, and without any very coarse granularity. Distinction into ectoplasm and endoplasm is not very noticeable. A few small food vacuoles are to be found in the cytoplasm.

The cilia are evenly distributed all over the body, except in the posterior region, where a few long cilia are to be found sticking out from a slight posterior prominence. These are about a quarter the length of the body of the ciliate. The ordinary cilia sweep with a very definite motion backwards over the surface of the body. They are arranged in longitudinal rows, giving the animal a striated appearance; there seem to be about thirty-five of these rows on each of the lateral surfaces of the body, a number that appears to be constant.

Towards the posterior end of the ciliate is a well-marked contractile vacuole. In position it lies somewhat nearer the oral border. It is not perfectly spherical, but is apparently compressed out of shape, so that it appears more as an irregular ellipse. Its expansion is so slow that it is not possible to observe its enlargement; but the systole is very rapid and sudden.

The mouth (Fig. 2), which is the most distinctive feature in this Protozoon, is a curiously shaped structure, situated about a quarter the way from the anterior end of the body. It lies on the edge formed by the two lateral borders. It consists of an invagination of the pellicle, which looks as if it were thrown into a number of folds, the whole being supported by a conspicuous horseshoe-shaped structure, which appears to be a continuation of the pellicle. In form, this apparatus is a little reminiscent of a section of a mammalian kidney, with a number of ducts opening into the pelvis. It gives the impression of being a kind of flattened sucker-like organ, which may be capable of evagination for the ingestion of food. No such movement has, however, been observed; and it is 
not known in what way this apparatus works. From this "pelvis" there runs a gradually narrowing cone-shaped passage leading down into the endoplasm. This, which is presumably the gullet, lies on a different level from the sucker-like organ. In a specimen lying with the mouth on the right side, the gullet may be seen to be running obliquely upwards towards the mouth. No cilia have been observed in this or in any other part of the mouth apparatus.

The meganucleus is a subspherical body situated in the centre of the organism, and is about $13 \mu$ in diameter. It stains heavily, forming a dense opaque mass with a number of indentations at the surface. Its position in a living specimen can fairly readily be seen as a comparatively clear space.

The micronucleus can, as a rule, be seen only with difficulty even in stained specimens, as it appears to lie laterally to the meganucleus.

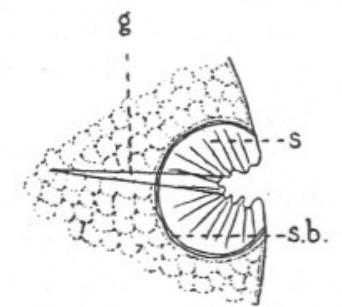

Fig. 2. Mouth apparatus of $P$. thalassemo. $\times 1350$ approx. g., gullet ; s., folded suckerlike organ ; s.b., supporting bar to sucker-like organ.

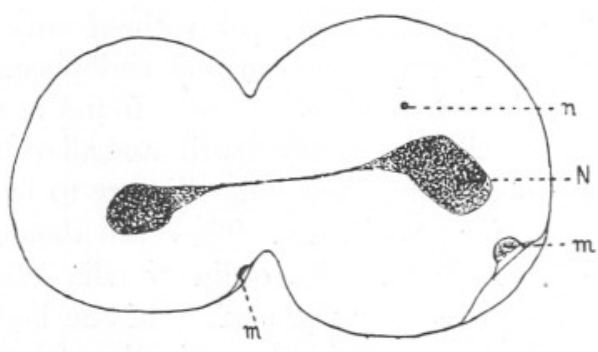

Frg. 3. P. thalassemo in division. $\times 550$ approx. $m$. , mouth; N., meganucleus ; n., micronucleus.

Consequently in most specimens it is obscured by the opacity of the meganucleus. In fact, I have only observed it with any certainty in an individual undergoing division, where in one of the daughter ciliates I have seen it as a small, rather faintly stained, round dot, lying a little distance from the meganucleus.

Division has only been observed in this one instance, which is shown in Fig. 3. It is a late stage, the micronucleus having divided, while the two daughter meganuclei are just completing their separation.

Conjugation has not been observed.

\section{Systematic Position.}

This ciliate belongs to the Holotricha, and, owing to the structure of its mouth, should probably be included among the Gymnostomata. I have been unable to find any form to which it bears much resemblance. The nearest appears to be Clathrostoma viminale, described by Penard (1922). This type also possesses a kind of sucker-like mouth, but it is 
not supported by any bar. Moreover, the sucker which " peut s'épanouir comme une ventouse circulaire," is perforated by the gullet, which leads into the endoplasm, whereas in the ciliate under consideration the gullet passes down to one side at a different level.

It seems necessary, therefore, to create a new genus, Ptyssostoma, making $P$. thalassema the type species, of which the following is a diagnosis.

\section{Ptyssostoma thalassema nov. gen., nov. sp.}

Somewhat flattened holotrichous gymnostomatous ciliate, with one side more convex than the other; the mouth situated about a quarter the way from the anterior end, consisting of a kidney-shaped, folded apparatus, supported by a horseshoe-shaped skeletal loop, with the gullet running obliquely into the endoplasm at a different level ; cilia arranged in about thirty-five longitudinal rows, with a group of a few long cilia at the posterior end ; anterior end of the body modified into a mobile prominence; meganucleus in the centre of the body, irregularly spherical; micronucleus apparently lying laterally to the meganucleus and generally hidden; contractile vacuole conspicuous and at posterior end.

Dimensions: $75-100 \mu$ by $55-75 \mu$.

Habitat: Intestine of Thalassema neptuni Gärtner, from Plymouth.

In conclusion, I wish to express my thanks to Dr. D. L. Mackinnon, of King's College, London, and to Mr. C. C. Dobell, F.R.s., for their kind help and criticism.

\section{REFERENCES.}

Florentin, R. (1898.) Sur un Nouvel Infusoire Holotriche, parasite des Phascolosomes: Cryptochilum Cuenoti (nov. sp.). Bull. Sc. France et Belg., XXXI, pp. 152-58, 1 Pl.

Lankester, E. R. (1881.) On Thalassema neptuni Gärtner. Zool. Anz., IV, pp. 350-56.

Penard, E. (1922.) Études sur les Infusoires d'Lau douce. Geneva. pp. 143-45. 
